\title{
Thyroid Disorders in Central Ghana: The Influence of 20 Years of Iodization
}

\author{
Osei Sarfo-Kantanka, ${ }^{1}$ Ishmael Kyei, ${ }^{1}$ Fred Stephen Sarfo, ${ }^{1,2}$ and Eunice Oparebea Ansah ${ }^{1}$ \\ ${ }^{1}$ Komfo Anokye Teaching Hospital, Kumasi, Ghana \\ ${ }^{2}$ Kwame Nkrumah University of Science \& Technology, Kumasi, Ghana
}

Correspondence should be addressed to Osei Sarfo-Kantanka; osarfokantanka21@gmail.com

Received 22 March 2017; Revised 16 May 2017; Accepted 28 May 2017; Published 4 July 2017

Academic Editor: Massimo Tonacchera

Copyright (C) 2017 Osei Sarfo-Kantanka et al. This is an open access article distributed under the Creative Commons Attribution License, which permits unrestricted use, distribution, and reproduction in any medium, provided the original work is properly cited.

\begin{abstract}
Background. Ghana began mandatory iodization of salt in 1996. This study compares the prevalence of thyroid disorders before and after the introduction of iodization. Methods. This is a retrospective study of thyroid cases from the middle belt of Ghana between 1982 and 2014. To demonstrate a link between iodization and hyperthyroidism and autoimmunity, we compared the prevalence of hyperthyroidism and autoimmune thyroid disorders before and after the iodization programme. Results. A total of 10,484 (7548 females, 2936 males) cases were recorded. The rate of thyroid cases seen was 343/100,000. Nontoxic nodular goiters $(25.7 \%)$ and toxic nodular goiters (22.5\%) represented the second commonest thyroid disorders recorded. The prevalence of hyperthyroid disorders seen after 1996 was significantly higher than the prevalence seen before the iodization ( 40.0 versus $21.1 \%, p<0.001$ ). The prevalence of autoimmune disorders recorded after iodization was significantly higher than that before the iodization programme started $(22.3 \%$ versus $9.6 \%, p<0.001)$. Conclusions. This study has revealed a significant increase in thyroid admissions in Central Ghana over the decades. A connection between iodine fortification and iodine-induced hyperthyroidism and between iodine fortification and autoimmune thyroiditis has been shown in this study.
\end{abstract}

\section{Introduction}

Thyroid disorders represent an important public health problem worldwide ranking second to diabetes as the commonest endocrinological disorder seen in adult medical practice and presenting a myriad of devastating consequences if not treated early $[1,2]$. The epidemiology and clinical features of thyroid disease are determined by the supply of iodine, an essential element in the synthesis of thyroid hormones [3-5]. Additionally, the presence of both excess and deficient iodine levels can pose adverse health effects [6]. Chronic iodine deficiency results in goiter formation and, if severe, hypothyroidism [7-9]. This can result in severe implications including cretinism, intellectual impairments, increased pregnancy loss, and infant mortality [9-11]. SubSaharan Africa has for a long-time been classified as an area of moderate to severe iodine deficiency [12-17]. Thyroid disorders on the continent represent over $25 \%$ of the global burden of the disease [18].
The drive by the World Health Organisation and the United Nation International Children Emergency Fund towards the elimination of iodine deficiency disorders through universal iodization of salt and other food products has so far achieved mixed results, particularly on the African continent [14, 19-21]. Whereas persistent wars and famine coupled with difficulties in implementation and regulation of iodine nutrition have eroded some of the gains made towards sufficient iodine intake on parts of the continent [22-24], excessive intake of iodine has been recorded in other areas of the continent $[25,26]$. World Health Organisation reports show that adequate or excessive iodine intake borne out of the universal iodization programme has been observed in over 30 countries, some of them on the African continent [2730]. Aghini-Lombardi et al. in Italy [31, 32], comparing the prevalence of various thyroid disorders in an initial region of severe iodine deficiency before and after the introduction of iodated salt in 1995 in Italy, revealed a reduction in the prevalence of nodular goiter from $46 \%$ to $25 \%$, whereas 
hyperthyroidism and autoantibody levels increased significantly. In Sub-Saharan Africa, a rise in the incidence of thyrotoxicosis was noted by physicians in Zimbabwe and the Democratic Republic of Congo following the introduction of iodized salt in both countries [29, 30].

In Ghana, efforts to reduce endemic iodine deficiency started with the adoption of universal salt iodization programme in the beginning of 1996 [25]. However, the lack of proper institutions to monitor and coordinate activities to ensure a smooth sailing programme devoid of undernutrition and excess iodine nutrition has meant only about $32.5 \%$ coverage has been achieved in some areas, while in other areas overexposure of iodine has meant an increase in toxic thyroid disorders [23]. The need therefore has arisen for a comprehensive evaluation of the effect of the 20-year-old universal iodization programme in Central Ghana.

Hospital-based data, although not entirely representative of the community-based setting, provides useful evidence of admission trends while also serving as sentinel reflecting the characteristics of thyroid disorders as what exists in the community. Understanding the temporal changes in thyroid admissions and presentation would therefore be instrumental in predicting the influence of iodization on the epidemiology and clinical presentation of thyroid disease in Ghana. The aim of this study was to assess the trends in demography and clinical characteristics of thyroid admissions from records at a tertiary referral hospital in Kumasi, situated in the middle belt of Ghana between 1982 and 2014.

\section{Methods}

2.1. Study Design and Setting. This is a retrospective study conducted at Komfo Anokye Teaching Hospital, a 1000-bed hospital located at the middle part of Ghana. It is the only tertiary referral hospital serving an estimated population of 10 million people from 6 out of 10 administrative regions of Ghana as well as other neighboring countries. A review of hospital admissions from 1982 to 2014 was performed at the hospital registry. Thyroid outpatient cases seen during the period were obtained from tally cards and the relevant information extracted unto a questionnaire. Among data extracted from the tally cards were age, gender, year of admission, and type of thyroid disorder and these were entered into excel sheets by data entry clerks. Thyroid disease type and diagnosis were classified using the International Classification of Diseases (ICD) codes ICD-9 (from 1983 to 1996) and ICD-10 (from 1997 to 2014). Rates of thyroid cases were expressed as thyroid cases seen per year divided by total number of outpatient cases seen. We considered diagnosis of toxic adenoma, toxic multinodular goiter, and Graves' disease, before and after the introduction of mandatory iodization in Ghana, to demonstrate the possible presence of iodine-induced hyperthyroidism; we considered diagnosis of Graves' disease and Hashimoto's thyroiditis before and after 2005 to demonstrate a link between the administration of iodine and thyroid autoimmunity.

2.2. Ethical Approval and Consent. This study was approved by the Committee on Human Research Publication and
Ethics of the School of Medical Sciences, Kwame Nkrumah University of Science and Technology, and the Komfo Anokye Teaching Hospital, Kumasi. Patient records/information were anonymized and deidentified prior to analysis.

2.3. Statistical Analysis. Means and medians were compared using either the Student $t$-test or Mann-Whitney $U$ test for paired comparisons and ANOVA or Kruskal-Wallis test for more than two group comparisons depending on whether continuous variables were parametric or nonparametric. A Poisson regression model was used to examine the temporal trends in the rates of thyroid admissions with categorical year variables. Exact Wilcoxon tests for ordered contingency tables, in the case of categorical characteristics, were used to study time trends. We considered the diagnosis of toxic adenoma/toxic nodular goiter/Graves' disease before and after the introduction of mandatory iodization in Ghana in 1996, to demonstrate the possible presence of iodine-induced hyperthyroidism; we considered diagnosis of Hashimoto's thyroiditis and Graves' disease before and after 1996 to demonstrate a link between the administration of iodine and thyroid autoimmunity. This was done using Pearson ChiSquare analysis. A two-sided $p$ value of $<0.05$ was considered significant in all statistical analysis with no adjustments made for multiple comparisons.

\section{Results}

3.1. Thyroid Admissions and Demography. Table 1 summarizes the demographic characteristics of this cohort of thyroid admissions. Ten thousand four hundred and eighty-four $(10,484)$ thyroid cases were seen between 1982 and 2014. This was made up of 7584 females and 2936 males with a ratio of $3.5: 1$. The average prevalence rate of thyroid cases seen between 1982 and 2014 was 343/100,000 admissions. As shown in Figure 1, proportions of female thyroid admissions ranged between $58 \%$ in 1982 and $81 \%$ in 1998. The crude incidence rate of thyroid admissions increased from 146/100,000 patients in 1982 to $426 / 100,000$ patients in 2012 . The increase in the rates of thyroid admission was highly significant $(p<$ $0.0001)$.

3.2. Characteristics of Thyroid Disorders. Table 2 summarizes the distribution and demographic characteristics of the various thyroid disorders seen over the study period. Nontoxic multinodular goiter represented the commonest thyroid disorder seen over the study period, representing over a quarter of all thyroid admissions. Toxic multinodular goiter represented the second commonest cause of thyroid admissions representing 22.5\%. Hypothyroidism, diffuse toxic goiter, nontoxic diffuse goiter, autoimmune thyroiditis, nontoxic adenoma, unspecified thyroiditis, nonspecified/other thyroid disorders, and toxic adenoma represented $13.1 \%, 12.1 \%, 6.6 \%$, $6.3 \%, 5.1 \%, 5.0 \%, 3.5 \%$, and $2.1 \%$ thyroid admissions, respectively. The median (IQR) age of admission and female: male ratio of patients for the various thyroid disorders were as follows: hypothyroidism: $34(32.5-52)$ and $2.2: 1$, nontoxic diffuse goiter: 48 (36-68) and $3.6: 1$, nontoxic thyroid nodule: 
TABLE 1: Demography and rates of thyroid disorders seen in Central Ghana from 1982 to 2014.

\begin{tabular}{|c|c|c|c|c|}
\hline Year & $\begin{array}{c}\text { Number of outpatients seen } \\
\text { in a year }\end{array}$ & $\begin{array}{c}\text { Number of thyroid cases } \\
\text { seen }\end{array}$ & $\begin{array}{c}\text { Thyroid cases per } 100,000 \\
\text { outpatients seen }\end{array}$ & $\%$ female thyroid cases \\
\hline 1982 & 59594 & 106 & 177.9 & 58.14 \\
\hline 1983 & 57544 & 82 & 146.0 & 65.79 \\
\hline 1984 & 62,474 & 144 & 230.5 & 61.29 \\
\hline 1985 & 67,938 & 136 & 200.2 & 67.24 \\
\hline 1986 & 74,774 & 134 & 179.2 & 68.42 \\
\hline 1987 & 74,768 & 198 & 265.9 & 74.16 \\
\hline 1988 & 74,098 & 188 & 253.7 & 69.15 \\
\hline 1989 & 76,114 & 174 & 228.6 & 59.42 \\
\hline 1990 & 75,168 & 198 & 263.4 & 70.79 \\
\hline 1991 & 73,626 & 170 & 230.9 & 73.85 \\
\hline 1992 & 69,634 & 166 & 241.9 & 76.19 \\
\hline 1993 & 75722 & 240 & 316.9 & 66.67 \\
\hline 1994 & 71404 & 252 & 352.9 & 76.98 \\
\hline 1995 & 70464 & 198 & 281.0 & 62.92 \\
\hline 1996 & 69710 & 236 & 338.5 & 74.62 \\
\hline 1997 & 79464 & 238 & 299.5 & 60.59 \\
\hline 1998 & 73974 & 202 & 273.1 & 81.32 \\
\hline 1999 & 104250 & 390 & 374.1 & 74.62 \\
\hline 2000 & - & - & - & - \\
\hline 2001 & 123,618 & 363 & 298.5 & 67.26 \\
\hline 2002 & 127824 & 417 & 326.2 & 77.78 \\
\hline 2003 & 127125 & 366 & 287.9 & 73.91 \\
\hline 2004 & 127,077 & 318 & 250.2 & 75.25 \\
\hline 2005 & 125976 & 393 & 312.0 & 76.58 \\
\hline 2006 & 111,402 & 474 & 425.5 & 76.58 \\
\hline 2007 & 132,138 & 510 & 386.0 & 79.46 \\
\hline 2008 & 131802 & 447 & 339.1 & 64.23 \\
\hline 2009 & 124,971 & 465 & 372.1 & 76.58 \\
\hline 2010 & 134,916 & 792 & 587.0 & 65.58 \\
\hline 2011 & 128,916 & 567 & 439.8 & 71.01 \\
\hline 2012 & 118,308 & 504 & 426.0 & 74.05 \\
\hline 2013 & 115,704 & 747 & 645.6 & 77.84 \\
\hline 2014 & 114,834 & 630 & 548.6 & 71.95 \\
\hline
\end{tabular}

TABle 2: Thyroid admissions in Central Ghana.

\begin{tabular}{lccc}
\hline Thyroid disorder & $N$ & Median age (IQR) & F:M ratio \\
\hline Hypothyroidism & $1362(13.1)$ & $34(32.5-52)$ & $2.2: 1$ \\
Nontoxic diffuse goiter & $703(6.6)$ & $48(36-68)$ & $3.6: 1$ \\
Nontoxic thyroid nodule & $535(5.1)$ & $34(32.5-52)$ & $9.0: 1$ \\
Nontoxic multinodular goiter & $2694(25.7)$ & $40(30-50)$ & $3.7: 1$ \\
Toxic multinodular goiter & $2359(22.5)$ & $36(27-42)$ & $8.3: 1$ \\
Toxic adenoma & $262(2.5)$ & $37(26-48)$ & $6.1: 1$ \\
Diffuse toxic goiter & $1269(12.1)$ & $56(21-76)$ & $4.9: 1$ \\
Thyroiditis unspecified & $524(5.0)$ & $23(31.5-48.5)$ & $2.4: 1$ \\
Autoimmune thyroiditis & $660(6.3)$ & $38(27-55)$ & $4.0: 1$ \\
Unspecified thyroid disease & $367(3.5)$ & & $3.4: 1$ \\
\hline
\end{tabular}




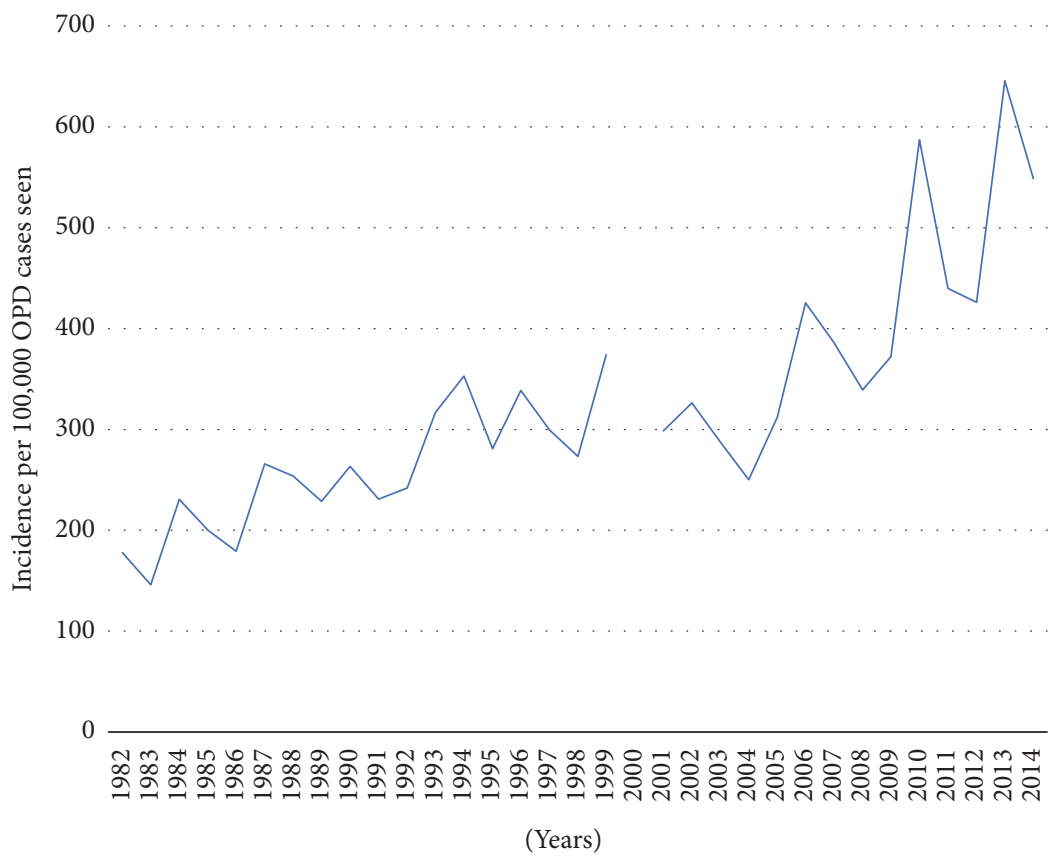

Figure 1: Trends in rates of thyroid admissions in Central Ghana.

TABLE 3: Temporal trends in incidence and characteristics of thyroid admissions in Central Ghana from 1982 to 2014.

\begin{tabular}{|c|c|c|c|c|c|c|}
\hline \multicolumn{2}{|l|}{ Characteristics } & 1982-1989 & 1990-1999 & $2001-2009$ & $2010-2014$ & $p$ value \\
\hline Number & & 1152 & 2290 & 3753 & 3240 & $<0.0001$ \\
\hline Incidence & 100,000 admissions & 212 & 229 & 417 & 648 & $<0.0001$ \\
\hline \multirow{2}{*}{ Age/years } & Mean & $43.3(18.5)$ & $44.8(18.8)$ & $41.3(14.1)$ & $43.1(15.3)$ & 0.7 \\
\hline & Median & $43(30-56)$ & $40(28-60)$ & $40(30-50)$ & $42(31.5-53)$ & 0.06 \\
\hline Women number (\%) & & $638(54.9)$ & $1456(66.3)$ & $2931(78.1)$ & $2631(81.2)$ & 0.0004 \\
\hline Hypothyroidism & E0 3.9 & $237(20.4)$ & $419(18.3)$ & $188(5.0)$ & $68(2.1)$ & $<0.0001$ \\
\hline Nontoxic diffuse goiter & E0 4.0 & $66(5.7)$ & $46(2.0)$ & $480(12.8)$ & $113(3.5)$ & 0.39 \\
\hline Nontoxic thyroid nodule & E0 4.1 & $41(3.5)$ & $121(5.3)$ & $274(7.3)$ & $113(4.4)$ & 0.02 \\
\hline Nontoxic MNG & E0 4.2 & $595(51.2)$ & $964(42.1)$ & $544(14.5)$ & $363(11.2)$ & $<0.0001$ \\
\hline Toxic MNG & EO 5.2 & $48(4.1)$ & $176(7.7)$ & $1.066(28.4)$ & $1260(38.9)$ & $<0.0001$ \\
\hline Toxic adenoma & & $2(0.3)$ & $32(1.4)$ & $109(2.9)$ & $136(4.2)$ & $<0.0001$ \\
\hline Diffuse toxic goiter & E0 5.0 & $50(4.3)$ & $137(6.0)$ & $454(12.1)$ & $713(22.0)$ & $<0.0001$ \\
\hline Thyroiditis unspecified & EO 6.9 & $12(2.1)$ & $30(2.9)$ & $34(2.6)$ & $27(2.5)$ & $<0.12$ \\
\hline Autoimmune thyroiditis & E0 6.3 & $24(3.8)$ & $66(5.4)$ & $198(5.1)$ & $324(10.0)$ & $<0.00001$ \\
\hline Unspecified thyroid/other disease & E0 7.9 & $40(3.4)$ & $57(2.5)$ & $161(4.3)$ & $62(1.9)$ & 0.32 \\
\hline
\end{tabular}

$34(32.5-52)$ and $9.0: 1$, nontoxic multinodular goiter: 40 (30-50) and $3.7: 1$, toxic multinodular goiter: $36(27-42)$ and $8.3: 1$, toxic adenoma: 35 (27-42) and 6.1:1, Graves' disease: 37 (26-48) and $4.9: 1$, unspecified thyroiditis: 56 (21-70) and $9.0: 1$, Hashimoto's thyroiditis: 23 (31.5-48.5) and $4.1: 1$, and other thyroid disorders: 38 (27-55) and $3.4: 1$. The difference in age of admission between the various thyroid disorders was highly significant $(p<0.0001)$.

\subsection{Temporal Trends in Thyroid Admissions}

3.3.1. Incidence and Demographic Trends. As shown in Table 3, there was an overall progressive increase in the incidence of thyroid cases in both absolute numbers and the rates per overall outpatient cases: $213 / 100,000$ admissions in the 1980 s to $538 / 100,000$ admissions in the 2010 s $(p<0.0001$ for linear trend). The trends in the age of thyroid admissions did not differ significantly over the decades. The proportion of female thyroid admissions increased significantly over the decades, increasing from $55.1 \%$ in the 1980 s to $82.7 \%$ in the 2010s ( $p<0.0001$ for trend).

3.3.2. Trends in Thyroid Disorders. There was a significant negative trend in cases of hypothyroidism recorded over the decades, decreasing from $28.2 \%$ of thyroid cases in the $1980 \mathrm{~s}$ to $12.1 \%$ in the 2010 s ( $p<0.002$ for trend). A significant 
TABLE 4: Differences in admission of thyroid disorders before and after iodization in Central Ghana.

\begin{tabular}{|c|c|c|c|}
\hline Thyroid disorder & $\begin{array}{c}1982-1995 \\
n=2385\end{array}$ & $\begin{array}{c}1996-2014 \\
n=8099\end{array}$ & $p$ value \\
\hline Graves' disease, $n(\%)$ & $124(5.2)$ & $1233(15.1)$ & $<0.0001$ \\
\hline $\begin{array}{l}\text { Toxic adenoma/toxic } \\
\text { nodular goiter, } n(\%)\end{array}$ & $403(16.9)$ & $2017(24.9)$ & $<0.0001$ \\
\hline Total, $n(\%)$ & $527(22.1)$ & $\begin{array}{c}3240 \\
(40.0)\end{array}$ & $<0.0001$ \\
\hline Graves' disease, $n(\%)$ & $124(5.2)$ & $1233(15.1)$ & $<0.00001$ \\
\hline $\begin{array}{l}\text { Autoimmune thyroiditis, } n \\
(\%)\end{array}$ & $105(4.4)$ & $583(7.2)$ & $<0.00001$ \\
\hline Total, $n(\%)$ & $229(9.6)$ & $1816(22.3)$ & $<0.0001$ \\
\hline
\end{tabular}

positive trend was observed for toxic multinodular goiter (3.6\% in the 80 s versus $46.3 \%$ in the 2010 s, $p<0.001$ for trend), nontoxic multinodular goiter (1.4\% in the 1980 s versus $4.7 \%$ in the 2010s, $p=0.02$ for trend), toxic adenoma ( $0.3 \%$ in the 80 s versus $4.2 \%$ in the $2010 \mathrm{~s}, p<0.001$ ), diffuse toxic goiter $(4.4 \%$ in the 80 s versus $45.4 \%$ in the 2010 s, $p<$ 0.001 for trend), unspecified thyroiditis ( $4.8 \%$ in the $80 \mathrm{~s}$ and $28.5 \%$ in the 2010s, $p<0.0001$ for trend), and autoimmune thyroiditis (3.8\% in the 1980 s versus $10.0 \%$ in the 2010 s, $p<$ 0.0001 for trend). Over the decades, proportion of cases due to nontoxic thyroid nodule, unspecified thyroiditis and other thyroid disorders did not charge significantly.

\subsection{Thyroid Disorders between 1982-1995 and 1996-2014}

3.4.1. Iodine Induces Thyrotoxicosis. As shown in Table 4, diagnosis of toxic multinodular goiter between 1982 and 1995 represented $16.9 \%$ of thyroid cases, while from 1996 to 2014 it increased to $24.9 \%$ of total thyroid cases ( $p<$ 0.0001). Diagnosis of Graves' disease between 1982 and 1995 was 5.2\%; it increased to $15.1 \%$ between 1996 and 2014, $p<0.0001$. The overall diagnosis of hyperthyroidism/ thyrotoxicosis increased significantly between the two time periods from $22.1 \%$ of thyroid admission to $40.0 \%$ of thyroid admissions. Comparing these results, there was a significant difference between the percentage of thyroid cases due to hyperthyroidism before and after the introduction of mandatory iodization. Prevalence of Hashimoto's autoimmune thyroiditis between 1982 and 1995 was 4.4\%; prevalence between 1996 and 2014 increased to 7.2\%. The overall diagnosis of autoimmune thyroid disorders over the 2 periods increased from $9.6 \%$ to $22.3 \%$. The difference between the 2 periods was statistically significance $(p<0.0001)$ (Table 5).

\section{Discussion}

This is the first study to examine the trajectory of thyroid disorders in Central Ghana before and after introduction of iodized salt in our subregion. We have shown an average incidence of 343/100,000 thyroid cases seen over the study period and an increasing trajectory of thyroid admission in the central belt of Ghana over the last three decades. This is reflected by both an increase in the absolute numbers of thyroid cases and the rate of thyroid cases expressed as the number of thyroid cases per total outpatient cases seen in the hospital over the period. The percentage of medical cases seen over the period due to thyroid disorders increased almost 4 -fold over the past three decades in our study. This finding is consistent with findings by Okosieme [10] and Ogbera and Kuku [19]; both recorded increasing incidence rates of thyroid disorders in the subregion. In a retrospective study in Accra, Ghana, in which histological diagnosis of thyroid disorders over a 6-year period from 2004 to 2010 was made, an annual incidence of 185.7 was recorded [33]. This, although lower than the incidence recorded by our study, is mitigated by the cross-sectional nature and the short duration of 6 years under the Accra study. Our study although retrospective was longitudinal with 32 years under study. The trend towards an increase incidence of thyroid disorders worldwide and especially in developing countries like Ghana has largely been explained by the increasing use of sophisticated imaging modalities such as highly sensitive ultrasound for thyroid examinations and third-generation immunoassays in diagnosis $[1,3]$. Additionally, Ghana like other countries in the African continent reports nutritional deficiencies including existing selenium deficiency $[1,4$, 23]. This has contributed to the erosion of some of the achievement made by the supplementation of iodine [14, 31]. Other endocrine disrupting chemicals such as thiocyanate levels, mostly found in Cassava (a staple food in most African countries) compete with iodine for thyroid hormone synthesis causing a persistence of iodine deficiency disorders [22].

In our study, females represented about $72 \%$ of the total thyroid admissions. Our study thus confirms several reports of a clear female gender predisposition to thyroid disease [1, $3,10]$. The increasing trends of thyroid dysfunction in females over the decades recorded in our study may be attributed to the increase of longitudinal trends in the number of autoimmune disorders diagnosed in our study. Autoimmune disorders by themselves have a significant predilection in females $[1,3,34,35]$.

Ghana an initial area with a moderate-severe iodine deficiency instituted mandatory iodization in 1996 [25]. Our results confirm that iodine supplementation especially in regions of moderate-severe iodine deficiency increases the incidence of overt hyperthyroidism from toxic adenoma, toxic multinodular goiter, and Graves' disease. Cerqueira et al. [36] and Pedersen et al. [37] demonstrated this finding by recording an increase in the prevalence of iodine-induced hyperthyroidism after mandatory iodization in Denmark. After universal iodine supplementation came into effect in 1995 in Zimbabwe, the incidence of hyperthyroidism in Zimbabwe increased from $2.8 / 100,000$ to $7.4 / 100,000$ per year [29]. A similar result was found in Zaire [30]. On the contrary, Yang et al. [38] and Teng et al. [39] in their studies failed to demonstrate a connection between iodine fortification and iodine-induced hyperthyroidism. Their studies were conducted in areas of only mild iodine deficiency. Their finding led them to conclude that the hyperthyroidism observed after iodine supplementation was not related to the amount of 
TABLE 5: Diagnostic criteria of various thyroid disorders.

\begin{tabular}{|c|c|}
\hline Thyroid disease & Diagnostic criteria \\
\hline \multicolumn{2}{|l|}{ Nodule } \\
\hline Single nodule & Normal thyroid volume with a single nodule $>3 \mathrm{~mm}$ in diameter \\
\hline Multiple nodules & Normal thyroid volume with $\geq 2$ nodules $>3 \mathrm{~mm}$ in diameter \\
\hline \multicolumn{2}{|r|}{ 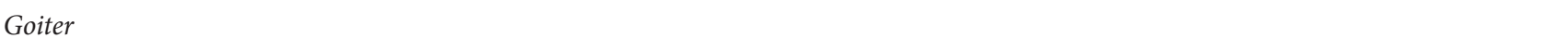 } \\
\hline Diffuse & Diffusely increased left and right lobes without nodules on ultrasound \\
\hline Nodular & $\begin{array}{l}\text { Asymmetrical increased left and right lobes or no increase size on ultrasound; irregular } \\
\text { dark dense echoes and numerous nodules throughout the thyroid gland }\end{array}$ \\
\hline Hyperthyroidism & $\mathrm{TSH}<0.25 \mathrm{Miu} / \mathrm{mL}, \mathrm{FT} 4>24 \mathrm{pmol} / \mathrm{L}$, or FT3 $>6.8 \mathrm{pmol} / \mathrm{L}$ \\
\hline Hypothyroidism & $\mathrm{TSH}>5.0 \mathrm{Miu} / \mathrm{mL}, \mathrm{TSH}<12.0 \mathrm{pmol} / \mathrm{L}$ \\
\hline \multicolumn{2}{|l|}{ Autoimmune thyroid disease } \\
\hline Graves' disease & Hyperthyroidism, diffuse goiter on ultrasound, TPOAb $>34 \mathrm{U} / \mathrm{mL}$, or TRAb $>5 \mathrm{U} / \mathrm{mL}$ \\
\hline Hashimoto's thyroiditis & $\begin{array}{l}\text { Hypothyroidism, TPOAb }>34 \mathrm{U} / \mathrm{mL} \text {, or TGAb }>115 \mathrm{U} / \mathrm{mL} \text { Diffuse goiter on ultrasound } \\
\text { without history of thyroid surgery }\end{array}$ \\
\hline Reference ranges & $\begin{array}{l}\text { FT3: 3.7-10.4 pmol/L, FT4: 7.5-21.1 pmol/L, TSH: 0.25-5.0 IU/mL, TPOAb: >5.6 U/L, } \\
\text { TRAb > 4.2 U/L }\end{array}$ \\
\hline TRAb: thyroid receptor antibody & \\
\hline
\end{tabular}
backed by thyroid function tests.

iodine administrated but was related to the level of iodine deficiency in the area studied, before mandatory iodization.

We have also demonstrated a statistically significant increase in the prevalence of autoimmune thyroid disorders in our hospital after the introduction of mandatory iodization in Ghana. This finding agrees with findings from Pedersen et al. [40], Li et al. [41], and Aghini-Lombardi et al. [31, 32]. Although the exact mechanism by which iodide induces thyroiditis is still unclear, several hypotheses have evolved. These include the presence of excess iodine inducing the production of cytokines and chemokines that can recruit immunocompetent cells to the thyroid, processing of excess iodine in thyroid epithelial cells resulting in elevated levels of oxidative stress and leading to harmful lipid oxidation and thyroid tissue injuries, and iodine incorporation in the protein chain of thyroglobulin augmenting the antigenicity of this molecule. Zimmermann and Andersson [16] on the contrary could not show an increase of thyroid autoantibodies after daily use of iodized salt in Morocco. This contrary finding may be attributed to the strong genetic predisposition to development of autoimmune disease.

The main limitation of this study is the absence of data on thyroid function tests, thyroid autoantibody profile, and lipid profiles. This study is also limited by the lack of detailed demographic and other clinical variables which could explain the increasing incidence of thyroid cases. Lastly, the levels of urinary iodine levels, a measure of iodine adequacy in a patient, were not measured as well as ultrasound measures of thyroid volume. These limitations raise important questions for further studies in helping to elucidate the increasing incidence of thyroid disorders and the changing epidemiology in Ghana. These notwithstanding, we have captured and presented a longitudinal trend in thyroid cases over a 32-year period noting an increasing trend in thyroid cases with a changing epidemiology towards hyperthyroidism and autoimmunity.

It is apparent that the pattern of thyroid disorders is evolving in Central Ghana with increasing iodine sufficiency. Although the primary goal of salt iodination remains the prevention of brain damage due to iodine deficiency, the risks associated with excess iodine replacement in Central Ghana require that attention be paid to increased monitoring of iodization and its effects.

In conclusion, we have shown in this study that the absolute and proportionate numbers of thyroid cases have increased over the past three decades in Central Ghana. There is a progressive increase in the prevalence of hyperthyroid and autoimmune thyroid disorders. These observations should prompt urgent concerted and coordinated efforts at monitoring iodine intake and levels in Central Ghana. While consolidating the present gains, salt iodination programmes must now be subjected to stringent review and monitoring.

\section{Conflicts of Interest}

The authors declare that they have no conflicts of interest.

\section{References}

[1] M. P. J. Vanderpump, “The epidemiology of thyroid disease," British Medical Bulletin, vol. 99, no. 1, pp. 39-51, 2011.

[2] A. O. Ogbera, O. A. Fasanmade, and O. Adediran, "The scope of cardiac complications of thyrotoxicosis in Lagos, Nigeria," Pakistan Journal of Medical Sciences, vol. 23, pp. 651-655, 2007.

[3] W. M. G. Tunbridge, D. C. Evered, R. Hall et al., "The spectrum of thyroid disease in a community: the Whickham survey," Clinical Endocrinology, vol. 7, no. 6, pp. 481-493, 1977. 
[4] M. B. Zimmermann, P. L. Jooste, and C. S. Pandav, "Iodinedeficiency disorders," The Lancet, vol. 372, no. 9645, pp. 1251$1262,2008$.

[5] WHO, UNICEF, and ICCIDD, Eds., Assessment of Iodine Deficiency Disorders and Monitoring Their Elimination: A Guide for Programme Managers, World Health Organization, Geneva, 2007.

[6] E. Brotfain, L. Koyfman, A. Frenkel, A. Smolikov, A. Zlotnik, and M. Klein, "Iodine-induced hyperthyroidism—an old clinical entity that is still relevant to daily ICU practice: a case report," Case Reports in Endocrinology, vol. 2013, Article ID 792745, 4 pages, 2013.

[7] M. B. Zimmermann, "Iodine deficiency," Endocrine Reviews, vol. 30, no. 4, pp. 376-408, 2009.

[8] A. M. Leung and L. E. Braverman, "Iodine-induced thyroid dysfunction," Current Opinion in Endocrinology, Diabetes and Obesity, vol. 19, no. 5, pp. 414-419, 2012.

[9] R. E. Black, L. H. Allen, Z. A. Bhutta et al., "Maternal and child undernutrition: global and regional exposures and health consequences," The Lancet, vol. 371, no. 9608, pp. 243-260, 2008.

[10] O. E. Okosieme, "Impact of iodination on thyroid pathology in Africa," Journal of the Royal Society of Medicine, vol. 99, no. 8, pp. 396-401, 2006.

[11] P. O. D. Pharoah, I. H. Buttfield, and B. S. Hetzel, "Neurological damage to the fetus resulting from severe iodine deficiency during pregnancy," The Lancet, vol. 297, no. 7694, pp. 308-310, 1971.

[12] F. Delange, B. de Benoist, and D. Alnwick, "Risks of iodineinduced hyperthyroidism after correction of iodine deficiency by iodized salt," Thyroid, vol. 9, no. 6, pp. 545-556, 1999.

[13] A. M. Leung and L. E. Braverman, "Consequences of excess iodine," Nature Reviews Endocrinology, vol. 10, no. 3, pp. 136142, 2013.

[14] E. N. Pearce, M. Andersson, and M. B. Zimmermann, "Global iodine nutrition: where do we stand in 2013?” Thyroid, vol. 23, no. 5, pp. 523-528, 2013.

[15] M. B. Zimmermann, "Iodine deficiency and excess in children: worldwide status in 2013," Endocrine Practice, vol. 19, no. 5, pp. 839-846, 2013.

[16] M. B. Zimmermann and M. Andersson, "Update on iodine status worldwide," Current Opinion in Endocrinology, Diabetes and Obesity, vol. 19, no. 5, pp. 382-387, 2012.

[17] J. Vanderpas, "Nutritional epidemiology and thyroid hormone metabolism," Annual Review of Nutrition, vol. 26, pp. 293-322, 2006.

[18] World Health Organization, Annex 3: Burden of disease in DALYs by cause, sex and mortality stratum in WHO regions, estimates for 2001, World Health Report, Geneva, http://www.who.int/whr/2002/whr2002_annex3.pdf, 2002.

[19] A. Ogbera and S. Kuku, "Epidemiology of thyroid diseases in Africa," Indian Journal of Endocrinology and Metabolism, vol. 15, 2, pp. S82-S88, 2011.

[20] A. R. K. Adesunkanmi and O. N. Makinde, "Goitre prevalence in pregnant women attending antenatal clinic in a teaching hospital," Journal of Obstetrics and Gynaecology, vol. 23, no. 2, pp. 156-159, 2003.

[21] https://www.unicef.org/wsc/goals.htm, accessed 6th November 2016.

[22] I. Taga, V. A. S. Oumbe, R. Johns, M. A. Zaidi, J. N. Yonkeu, and I. Altosaar, "Youth of west-Cameroon are at high risk of developing IDD due to low dietary iodine and high dietary thiocyanate," African Health Sciences, vol. 8, no. 3, pp. 180-185, 2008.

[23] H. S. Izzeldin, M. A. Crawford, and P. L. Jooste, "Population living in the Red Sea State of Sudan may need urgent intervention to correct the excess dietary iodine intake," Nutrition and Health, vol. 18, no. 4, pp. 333-341, 2007.

[24] A. J. Seal, P. I. Creeke, D. Gnat, F. Abdalla, and Z. Mirghani, "Excess dietary iodine intake in long-term African refugees," Public Health Nutrition, vol. 9, no. 1, pp. 35-39, 2006.

[25] R. O. Nyumuah, T.-C. C. Hoang, E. F. Amoaful et al., "Implementing large-scale food fortification in Ghana: lessons learned," Food and Nutrition Bulletin, vol. 33, 3, no. 4, pp. S293S300, 2012.

[26] F. C. Kelly and W. W. Snedden, "Prevalence and geographical distribution of endemic goitre," Bulletin of the World Health Organization, vol. 18, no. 1-2, pp. 5-173, 1958.

[27] A. Mostbeck, G. Galvan, P. Bauer et al., "The incidence of hyperthyroidism in Austria from 1987 to 1995 before and after an increase in salt iodization in 1990," European Journal of Nuclear Medicine, vol. 25, no. 4, pp. 367-374, 1998.

[28] F. Delange, A. Robertson, E. McLoughney, and G. Gerasimov, Elimination of Iodine Deficiency Disorders (IDD) in Central and Eastern Europe, the Commonwealth of Independent States and the Baltic States, WHO, Geneva, Switzerland, 1997.

[29] C. H. Todd, T. Allain, Z. A. R. Gomo, J. A. Hasler, M. Ndiweni, and E. Oken, "Increase in thyrotoxicosis associated with iodine supplements in Zimbabwe," The Lancet, vol. 346, no. 8989, pp. 1563-1564, 1995.

[30] P. P. Bourdoux, A. M. Ermans, A. Mukalay wa Mukalay, S. Filetti, and R. Vigneri, "Iodine-induced thyrotoxicosis in Kivu, Zaire," Lancet, vol. 347, pp. 552-553, 1996.

[31] F. Aghini-Lombardi, L. Antonangeli, E. Martino et al., "The spectrum of thyroid disorders in an iodine-deficient community: the Pescopagano survey," Journal of Clinical Endocrinology and Metabolism, vol. 84, no. 2, pp. 561-566, 1999.

[32] F. Aghini-Lombardi, E. Fiore, M. Tonacchera et al., “The effect of voluntary iodine prophylaxis in a small rural community: the pescopagano survey 15 years later," The Journal of Clinical Endocrinology \& Metabolism, vol. 98, no. 3, pp. 1031-1039, 2013.

[33] E. M. Der, S. E. Quayson, J. N. Clegg-Lamptey, E. K. Wiredu, R. K. D. Ephraim, and R. K. Gyasi, "Thyroid disorders in Accra Ghana; a retrospective histopathological study at the Korle-Bu teaching hospital," Journal of Medical and Biomedical Sciences, vol. 2, no. 1, pp. 1-7, 2013.

[34] J. G. Hollowell, N. W. Staehling, W. D. Flanders et al., "Serum TSH, T4, and Thyroid Antibodies in the United States Population (1988 to 1994): National Health and Nutrition Examination Survey (NHANES III)," The Journal of Clinical Endocrinology of Metabolism, vol. 87, no. 2, pp. 489-499, 2002.

[35] A. P. Weetman and A. M. McGregor, "Autoimmune thyroid disease: further developments in our understanding," Endocrine Reviews, vol. 15, no. 6, pp. 788-830, 1994.

[36] C. Cerqueira, N. Knudsen, L. Ovesen et al., "Association of iodine fortification with incident use of antithyroid medication - A Danish nationwide study," Journal of Clinical Endocrinology and Metabolism, vol. 94, no. 7, pp. 2400-2405, 2009.

[37] I. B. Pedersen, P. Laurberg, N. Knudsen et al., "Increase in incidence of hyperthyroidism predominantly occurs in young people after iodine fortification of salt in Denmark," Journal of Clinical Endocrinology and Metabolism, vol. 91, no. 10, pp. 38303834, 2006. 
[38] F. Yang, Z. Shan, X. Teng et al., "Chronic iodine excess does not increase the incidence of hyperthyroidism: A propective community-based epidemiological survey in China," European Journal of Endocrinology, vol. 156, no. 4, pp. 403-408, 2007.

[39] W. Teng, Z. Shan, X. Teng et al., "Effect of iodine intake on thyroid diseases in China," New England Journal of Medicine, vol. 354, no. 26, pp. 2783-2793, 2006.

[40] I. B. Pedersen, N. Knudsen, T. Jørgensen, H. Perrild, L. Ovesen, and P. Laurberg, "Large differences in incidences of overt hyperand hypothyroidism associated with a small difference in iodine intake: A prospective comparative register-based population survey," Journal of Clinical Endocrinology and Metabolism, vol. 87, no. 10, pp. 4462-4469, 2002.

[41] Y. Li, D. Teng, Z. Shan et al., "Antithyroperoxidase and antithyroglobulin antibodies in a five-year follow-up survey of populations with different iodine intakes," Journal of Clinical Endocrinology and Metabolism, vol. 93, no. 5, pp. 1751-1757, 2008. 


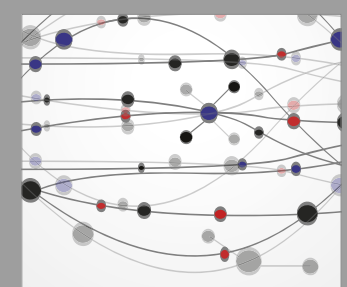

The Scientific World Journal
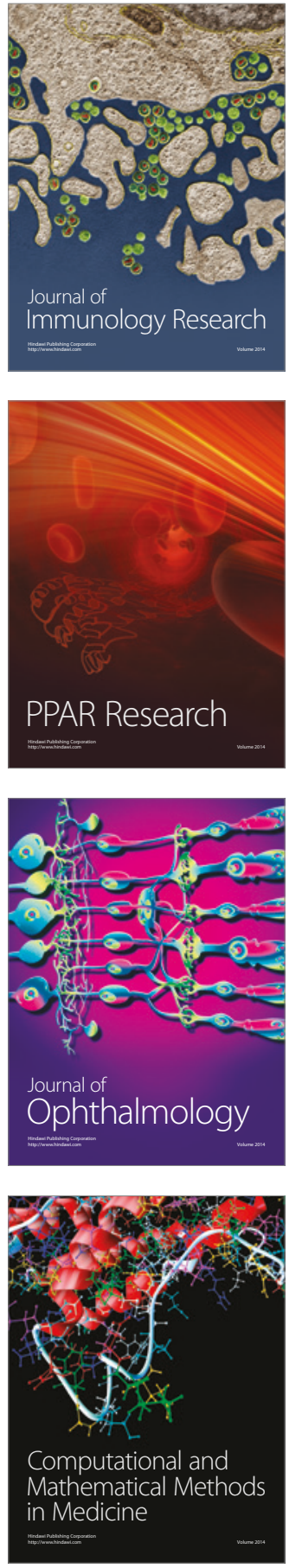

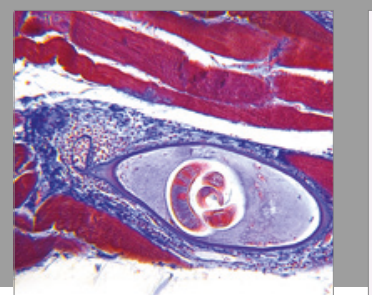

Gastroenterology Research and Practice
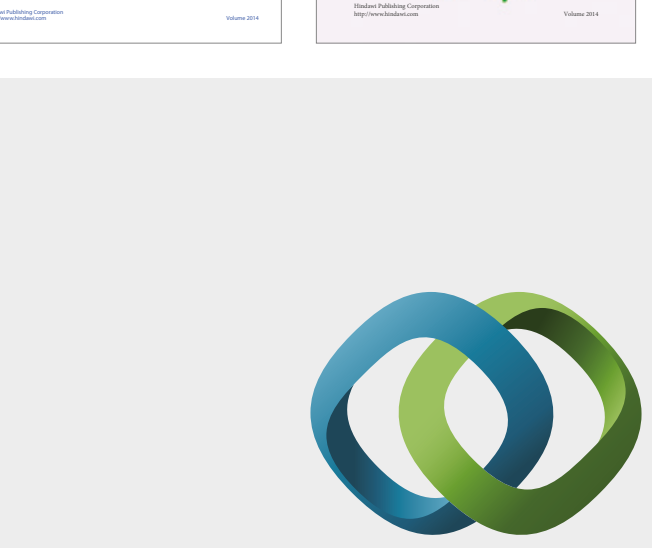

\section{Hindawi}

Submit your manuscripts at

https://www.hindawi.com
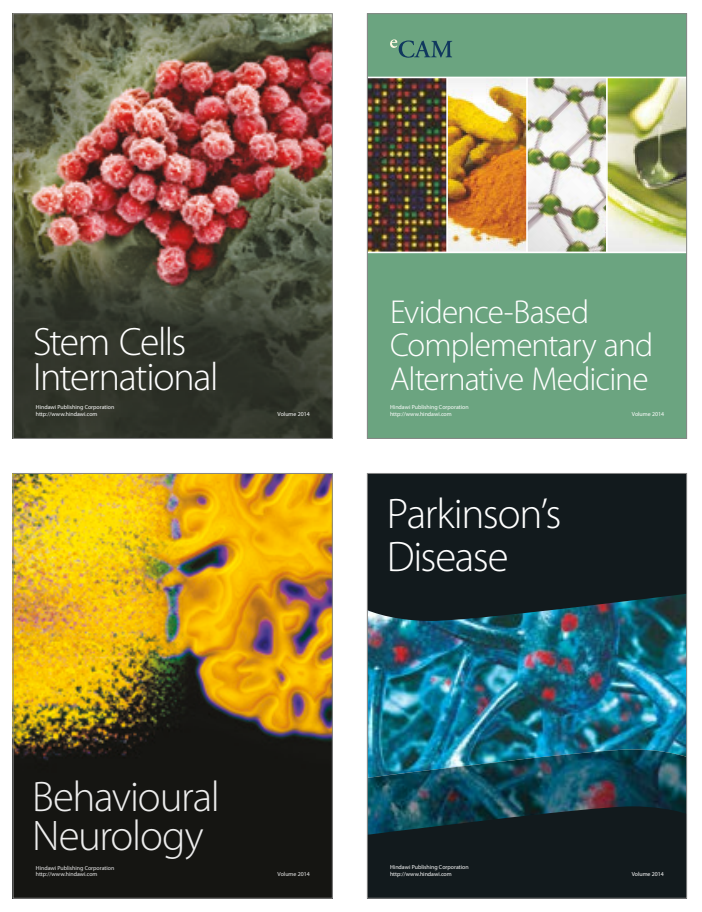
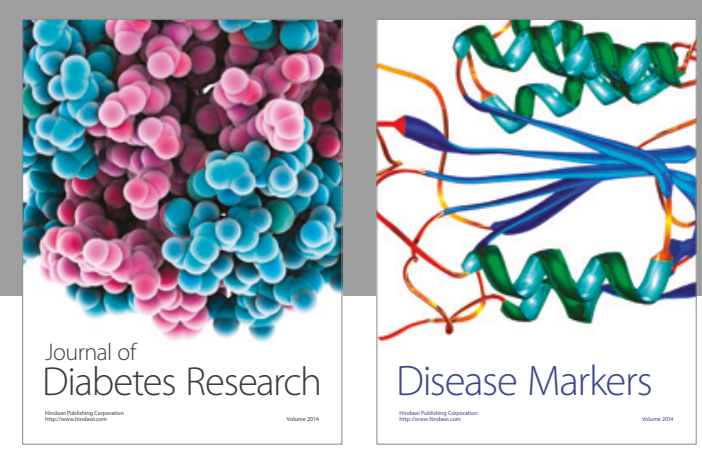

Disease Markers
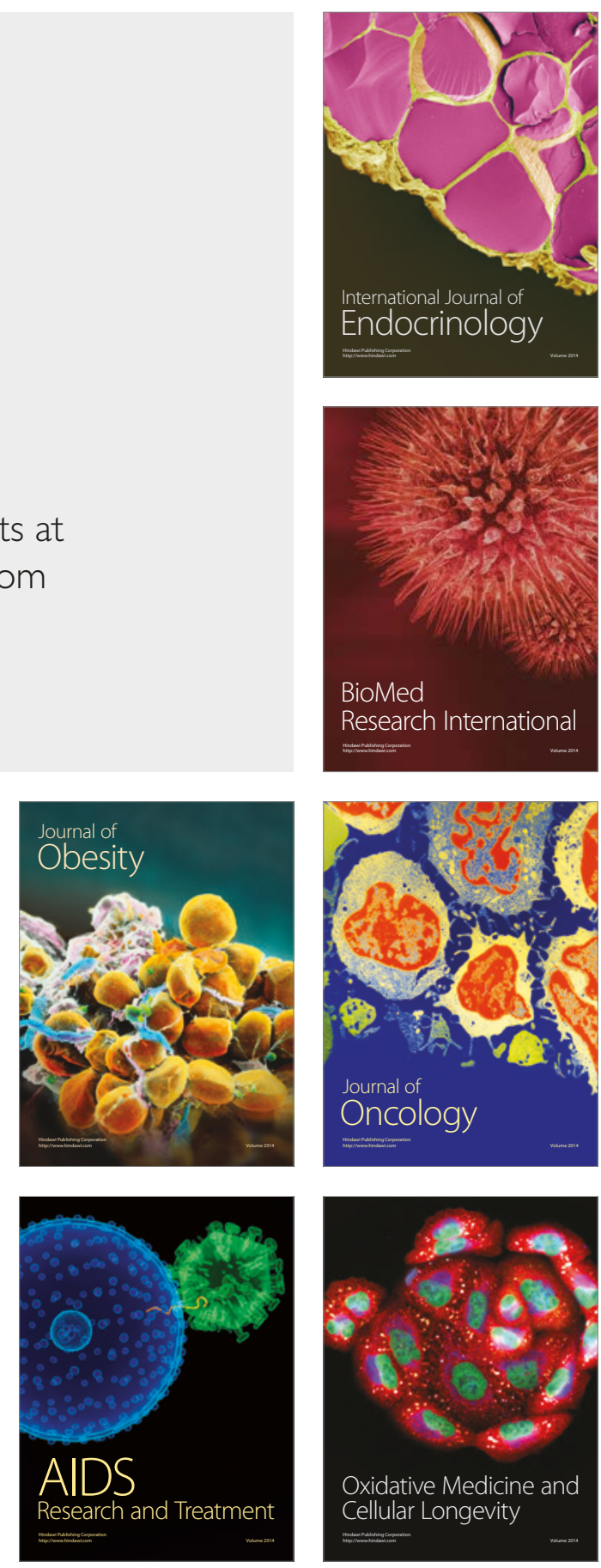